Artículos 



\title{
Presentimiento de la ciudad fronteriza (sobre la Politeia de Platón)
}

\author{
Eugenio Trías
}

$\mathbf{P}$ ara que se dé el milagro que siempre constituye la emergencia de la filosofía se requieren dos condiciones: que se produzca un radical distanciamiento respecto a la obviedad, y que se elija un contrincante de entidad y valía semejante a la del que se mide con él. La mejor prueba de que un escrito no es filosófico se halla en la transigencia con lo obvio, y en el uso de un adversario de nula entidad y solvencia. Reducir la cabeza del enemigo al modo jíbaro es la más segura prueba de que un discurso no pretende ponerse a prueba. Y una filosofía que no acepta ese envite no puede justificarse como tal.

La grandeza de la República de Platón puede advertirse ya desde su primer libro. En él se plantea la cuestión crucial que atraviesa el diálogo de parte a parte: la justicia. Pero en lugar de examinar en positivo este difícil asunto, Platón deja que irrumpa un enemigo de avasalladora vitalidad que genera una dificultad casi insuperable en su adversario (Sócrates).

No se plantea a través del joven Trasímaco la esencia de la justicia sino algo mucho más inquietante. El terrible personaje irrumpe en la escena desestimando cualquier pretensión de acceso al tema del diálogo. Nada le importa la esencia ni la idea de justicia. Nada quiere saber de esencia, idea o sustancia. Sencillamente advierte que lo que importa es, frente a esas morosas aproximaciones dialécticas propias del eterno Sócrates, aceptar un veredicto que todo el mundo secretamente asume pese a contradecir cualquier amago de obviedad; y que pocos están dispuestos a contradecir, aunque nadie se atreva a confesar.

Trasímaco señala que lo importante no es saber qué es la justicia (con el fin de ejercerla y practicarla). Lo que verdaderamente importa (a la inmensa mayoría) es alcanzar un comportamiento que, pese a ser en su raíz profunda- 
mente injusto, pueda presentarse ante la opinión pública con el atributo de lo justo y conveniente.

Pero con el fin de reforzar los exabruptos de Trasímaco, más agresivos que reflexivos, más viscerales que inteligentes, los interlocutores de Sócrates, los hermanos Adiamanto y Glaucón, se hacen cargo del diálogo y procuran dar a las tesis del impetuoso joven una fuerza y una capacidad persuasiva que las hace verdaderamente difíciles de refutar.

Se planteará, en consecuencia, si es deseable la justicia "por ella misma" (y no tan sólo por las consecuencias que ella y su contraria, la injusticia, pueden acarrear). Se contará la historia del pastor Giges, que consiguió un anillo mágico con el cual se volvía invisible cuando el engaste se lo ponía de cara a la palma de la mano; una vez invisible, sedujo a la mujer del rey y se apoderó del reino; merced a su invisibilidad gobernó como un dios, rodeado de mortales.

Los buenos lo son contra su voluntad; son buenos porque no pueden ser malos.

El "contrato social" consiste en una suerte de término medio entre el mayor bien, que es cometer injusticia sin sufrir castigo, y el mayor mal, que consiste en no poder defenderse de la injusticia que se sufre. Los convenios y las leyes regulan esas posibilidades extremas; o existen para mitigarlas, en previsión de mayores males.

De hecho "no hay mayor perfección en el mal que el parecer bueno no siéndolo": el de alguien que, cometiendo las mayores fechorías, "goza de la más intachable reputación".

La sabiduría de este mundo nos induce a pensar que "no hay que querer ser justo (eínai) sino sólo parecerlo (dokeîn)". Pues el justo "será flagelado, torturado, encarcelado; le quemarán los ojos, y, tras haber padecido toda clase de males, será al fin empalado y aprenderá de este modo que no hay que querer ser justo sino sólo parecerlo". En cambio el injusto "ajusta su conducta a la verdad, y no a las apariencias, pues desea no parecer injusto, sino serlo".

De hecho toda la educación, la paideia, avalada por los grandes educadores en la vida que fueron los poetas (épicos, trágicos, líricos) no hace sino remachar esta suerte de máximas de sabiduría de la vida que orientan la conducta y la acción a obrar en consecuencia con ellas. Adiamanto concluye que esos educadores no se interesan lo más mínimo en la justicia por ella misma, sino tan sólo en la "consideración moral que de ella resulta".

Para lo cual importa parecer ser justo, con el fin de obtener cargos públicos, reputación, buenos matrimonios y hasta ser querido por los dioses; unos dioses impregnados de la misma sabiduría popular que les concedieron sus acuñadores, los poetas; una sabiduría de la vida convertida en estado general de opinión, humana y divina, con ese carácter de disimulada obviedad que posee todo lo que, pese a que no puede ser confesado, constituye el bagaje y 
el equipaje necesario para transitar sin desdoro, o sin ser aniquilado, por este "mundo inmundo" en que vivimos.

La responsabilidad de ese estado de opinión corresponde, por lo que puede advertirse, a la educación. Es una responsabilidad política, pública y ciudadana; de ella dependen los hábitos que componen las disposiciones mentales e intelectuales de quienes habitan la ciudad.

El modo de pensar de los ciudadanos, sus máximas de conducta, su orientación del ethos y la suerte de valores máximos que lo gobiernan son consecuencia de ese "estado de opinión" convertido en creencia firme, casi inconsciente, transmitida a través de poetas y educadores a maestros y progenitores, y de ellos a todos los ciudadanos.

\section{II}

Todo el diálogo de Platón, Politeia, consistirá en la paciente refutación de este listón en que colocan Glaucón y Adiamanto la cuestión de la justicia. Un mérito grande de esta obra radica en ese inquietante comienzo. No se plantea en positivo lo que la justicia pueda ser. Se plantea lo que la mayoría tiende a asumir en su práctica (aunque no en las coartadas morales con que ésta suele recubrirse). El diálogo cobra suma solvencia al sobreponerse a esa prueba.

Para lo cual Platón arbitra el conocido expediente de examinar esa virtud, la justicia, en el contexto aumentado en el cual su incidencia en el ánimo puede advertirse: el que la revela en la Ciudad.

Importa acudir a la oftalmología para efectuar ese examen, ya que no gozamos de buena vista, ni el modelo que necesitamos contemplar es perfectamente visible; capas y sedimentaciones de falsa y deficiente educación hacen la tarea difícil; acumulan escamas o cataratas en el ojo que quiere ver; o llenan de brumas o de espesas nieblas el paisaje que se intenta contemplar.

Será preciso leer en grandes letras, como las que usan los oculistas, el abecedario diminuto que permite deletrear la "justicia" en el hombre particular. Ese inventario de letras grandes lo constituye la ciudad.

Con lo que se ha suscitado, ya desde el comienzo, lo que compone el más grandioso leitmotiv del diálogo: la correlación entre el hombre singular, y su principio animador, el alma, y la ciudad en su conjunto; entre el Alma (con su compleja constitución, de la que se examinan sus tres partes principales) y la Ciudad (con sus segmentos deliberante y gobernante; auxiliar o guardián; y traficante o productivo, con artesanos, negociantes y comerciantes).

Se establecerá, al respecto, una triple correlación: entre las tres partes del alma, las tres virtudes (aretai, "excelencias") que pueden corresponderles, y las tres secciones en que la ciudad debe ser dividida. 
En ésta se destaca, ante todo, la clase gobernante, que se corresponde con la parte intelectual y deliberante del alma; la virtud que le es propia es la prudencia o sabiduría práctica (fronésis); sigue la clase guardiana de los auxiliares, en quienes se cultiva sobre todo la parte enérgica y animosa del alma, la voluntad y su carácter irascible, cual corresponde a la clase guerrera (thymos, oréxis). La virtud correspondiente es esa suerte de "opinión recta referida a lo que hay que temer", que es el valor, la valentía.

Por fin se halla la clase comercial, o económica, en la que prevalece la parte anímica relativa a necesidades y deseos; y la virtud que corresponde cultivar es, en ella, la templanza o moderación (sofrosyne): una suerte de "modo musical o armonía" (symfonía kai armonía) que confiere orden (cosmos) y dominio de los placeres y las concupiscencias, haciéndonos dueños de nosotros mismos.

De hecho, los gobernantes, o la parte inteligente del alma, debe poseer las tres virtudes reseñadas; los auxiliares, junto al coraje, que es su virtud propia, debe poseer también moderación; y a la clase económica le basta el cultivo de ésta (lo mismo que a la parte del alma que regula necesidades y deseos o placeres).

Conocidos estos tres elementos (en los tres ámbitos reseñados, de clases sociales de la ciudad, de partes del alma y de virtudes correspondientes) puede ser deducido por inferencia derivada de este recorrido el cuarto término, que constituye la incógnita $(=x)$ que el diálogo tiene que despejar: la definición precisa de la justicia.

Ésta será concebida como una suerte de virtud que concede armonía y proporción a todas las demás, situándolas a todas y cada una en su ámbito propio; y por tanto relacionándolas entre sí, de manera que jamás se pierda la unidad y totalidad orgánica del conjunto; y todo ello en correlación con la ciudad y sus segmentos sociales; y también en correspondencia con el alma y sus respectivas partes.

La injusticia puede ser, entonces, definida como una sedición de la parte contra el todo, en la que la parte (social, anímica o virtuosa) quiere prevalecer sobre la totalidad, o imponerse a la ciudad entera.

Y esa sedición que descubrimos en letras grandes en la ciudad, a modo de flagrante injusticia, es la misma que podemos advertir en el hombre singular, o en su alma específica: una parte se alza en armas, por así decirlo, contra la totalidad.

Como sucede en toda enfermedad, en la que un órgano inflamado, el hígado o el corazón, el cerebro o los riñones, parece atacado de hybris; y acaba devorando al conjunto, u obligando a éste a cuidar de él como único elemento existente; de manera que el organismo vital se deba plegar al servicio de esa parte orgánica que, de pronto, reclama, a través del tormento, o del peligro de desintegración y muerte, toda atención y cuidado. 
La justicia es, pues, una suerte de virtud de virtudes, reguladora de las demás, que asigna a cada una su lugar; del mismo modo como es "de justicia" que cada individuo o persona efectúe en la ciudad su ocupación y operación propia, su oficio y su labor encomendada, evitándose realizar otra cosa que aquella para lo cual ha sido educado por la propia ciudad.

La ciudad es, en su conjunto, regulada por la justicia, una "comunidad de goces y de penas" que si es justa goza de una "salud", en sentido médico, contraria a posibles excesos o defectos (hygeía té tis...). Y es lo que en términos musicales llamamos armonía (conjugación de modos en su justa proporción) o sinfonía (coordinación de instrumentos para promover un sonido armónico).

El razonamiento médico y musical se refuerzan; la salud es buena armonía; aquélla constituye una buena proporción (en el sentido hipocrático de la justa dosificación de humores, o de elementos).

La justicia es, pues, salud en sentido cívico, o psíquico, asegurada por esa suerte de meta-virtud que es la justicia, en la que todas las demás "excelencias" son unificadas y combinadas; o es armonía (musical) en ese mismo sentido cívico-anímico, de manera que se halle la proporción adecuada que concede el acorde sinfónico justo a esa armonía y buena proporción de segmentos urbanos, de las partes del alma correspondientes y de las virtudes específicas de cada parte o segmento; y todo ello bien pertrechada por una educación en la que los ejercicios gimnásticos y la educación musical son preponderantes; de este modo se va cultivando y educando el ejercicio que consolida los hábitos y las disposiciones virtuosas acordes con esa definición de la justicia.

\section{III}

Platón edifica, para el caso, una ciudad; y la construye con el más legítimo y frágil de los medios: la bella escritura. Kalípolis será el fruto de una escritura que discurre en forma de diálogo. En esa ciudad podrá hallarse, como se ha dicho, en la armonía musical (y medicinal) entre sus segmentos sociales, y sus correspondientes potencias anímicas, y excelencias éticas, lo que por justicia pueda entenderse.

Sin que esa investigación se dé así por cancelada. El diálogo culmina con la búsqueda de un fundamento para la propuesta conseguida. Acontece en el libro sexto, en el cual se indaga en el Bien (comparable al Sol) ese principio sin condiciones. Y una vez que se ha vislumbrado ese ámbito de la suprema de las Ideas se le impone a Sócrates un descenso a la realidad terrenal de la que originariamente se partió.

Insiste en el diálogo el doble plano de toda inauguración ciudadana: el celeste, en el que el augur (Sócrates) contempla el cielo, y los meridianos en 
los cuales circula y ronda el Sol en su despliegue de ideas, y el plano terrenal en el cual lo contemplado se proyecta.

Esa contemplación, o cum-templatio, traza el cruce de dichas ideas, todas ellas gobernadas o presididas por la idea suprema (el Bien, o el Sol). Ahora se trata de proyectar ese mundo ideal sobre la ciudad real. O de proponer, como en el viejo rito grecolatino de la inauguratio de la ciudad, que era de hecho un rito cosmológico y cosmogónico como el que Platón remachará en su cosmología en el Timeo, una caracterización de la ciudad que debe ser fundada.

Pero es preciso asimismo contemplar el estado de la ciudad previa a esa fundación; el estado en que la ciudad se halla cuando la política educativa, o la paideia, no ha sido orientada y guiada por la ruta metodológica trazada en este diálogo, sino que procede de los viejos educadores, verdaderos corruptores, que han creado los estados de opinión en cuyo marasmo naufragaban las opiniones relativas a la justicia y a la injusticia al comienzo de la conversación.

Se trata, por tanto, de contemplar el estado real de la ciudad cuando tal educación (filosófica) no se produce. Pero eso sucede después de que se ha ascendido a lo más empinado de la cima educativa, a sus formas más recónditas e inaccesibles, las que permiten escalar hasta el más subido conocimiento de la verdad, a la Idea suma y suprema. Tal es la idea del bien.

La teoría de las ideas ronda esta parte del diálogo (libro sexto). Si no se llega a las ideas "se vive en sueños", o se toma la sombra por el objeto; o no se logra despertar ni abrir de verdad los ojos (de par en par). El saber de quien conoce, frente al parecer de quien opina: tal es la seña distintiva del despierto y de quien vive en ensueños.

Una señal daimónica (tò daimónion sêmeíon) documenta a Sócrates sobre la necesidad de orientarse hacia la filosofía, retirándose de la política en su estado actual; único modo de refundar, desde el saber filosófico, la ciudad.

Hay que llegar, entonces, a las más grandes enseñanzas que la filosofía puede proporcionar; y eso significa la visión (e Idea correspondiente) que garantice tener los ojos abiertos de par en par; quizás por confrontarse con el Ojo mismo que ilumina todas las cosas, el Sol (Shakespeare le llama $O$ eye of eyes). Y Goethe comenta un célebre adagio clásico de manera hermosa:

"Wär nicht das Auge sonnenhaft,

Die Sonne könnt es nie erblicken".

"Si el ojo no fuese semejante al sol

El sol no podría ser nunca contemplado".

Ese helio-morfismo de la mirada asegura su posible contemplación solar, aun a riesgo de insolación y radical deslumbramiento. Ese Sol es, de todos 
modos, la imagen y metáfora del Mejor Sol, cuya aurora se alumbra en nuestra alma (y en la "bella ciudad"); ese Sol invisible, impalpable, Sol que alumbra y da vida a todas las virtudes, a la justicia y a las demás, y que las funda y fundamenta, ese Sol es el Bien; éste es el Don Mayor, El Don mismo en su radical naturaleza efusiva; es eso que se da al darse como lo que es, Don y sólo Don: regalo, efusión. Como el Sol que se halla harto de su propia repleción, colmado y pleno de luz que da y regala, al comienzo de Así habló Zaratustra.

Ese Bien es lo más viejo y venerable (presbeía) de todo lo existente; posee más dinamismo y fuerza, o potencia (dynamis), que cuanto existe y se da; está por tanto más acá y más allá, o por encima, del ser que existe, y de su disposición esencial; está por encima de la esencia (ousía), pues la da y concede en su efusión.

Allende (hepekeina) esencia o sustancia (tês ousías) vive esa fuente hiperbólica e hiperbórea, principio rector de todo lo vivo y existente, dador de ser, vida y sentido, generador y gestador de inteligencia y vida. Un ser por encima del ser, cuya naturaleza y esencia consiste en darse, como don, a la existencia, dotándole de vida; y en darse como don lumínico a la inteligencia, dotándole de capacidad de comprensión y expresión lógico-lingüística. Ese ser goza, pues, de una "maravillosa y daimónica naturaleza hiperbólica" (daimonías úperbolês).

Constituye un principio no hipotético (arjen ànupótheton). Es, pues, la parte más brillante del ser (tó fanótaton tổ óntos). Llegarse a él es lograr la cima de la ascensión educativa (ànábasis). Ese Bien constituye el Centro mismo al que toda esta reforma educativa, ejecutada por la vía filosófica, se orienta. El Bien encarna el Centro y el "poder del Centro".

De este modo se establece en el diálogo, de manera inequívoca, eso que Mircea Eliade llama así ("poder del centro") en un célebre artículo sobre el "simbolismo del centro" en la fundación inaugural de las ciudades.

La inauguratio era un ritual ceremonial cosmogónico y cosmológico; el centro de la ciudad, "contemplado" en el cielo (en virtud de la observación del augur, o cum-templatio) y proyectado sobre el ágora, era el centro y ombligo mismo del cosmos (así recreado o refundado); recreado a través de ese ritual simbólico que avalaba la intersección de todos los estratos cósmicos, cielo, tierra y subsuelo, a través del desglose de tres momentos: el momento contemplativo del ritual; el segundo momento de proyección en la cuadrícula ciudadana del templo (recorte, demarcación) entre-cruzado en el cielo, ahí donde los meridianos se juntan, concediendo lugar idóneo (templo) a lo observado en el cielo (o con-templado).

En ese segundo momento se proyectaba el cruce de meridianos celestes, Cardus y Decumanos, sobre las dos avenidas entrecruzadas en tierra, el ágora central y los cuadrantes o cuarteles correspondientes, o barrios principales 
de la cuadrícula ciudadana; el rito se culminaba con la asignación de Límites, y la apertura de Puertas, a la circunscripción mural del recinto urbano, así determinado, definido, a modo de cerco específico de todo lo que en él pudiera darse, o pudiera ser habitado y convivido.

Y por último (tercer momento del ritual) se excavaba un pozo llamado en latín mundo, mundus, "mundo inmundo", que a modo de cripta cósmica reproducía en su bóveda el rito contemplativo, guardaba los legados o reliquias de la fundación, de la ciudad originaria de la cual la fundada era colonia, y del héroe fundador de aquélla (recordada en ésta); y se mantenía cerrada la losa que impedía el acceso del subsuelo o del Hades, salvo en fechas señaladas.

Ese "mundo inmundo" será, sin duda, el modelo platónico de su aproximación a una ciudad que vive en sueños, que vive esta vida como la triste existencia de las almas muertas en el Hades, y que sufre esa opresión por las cadenas que la falta de educación, o la mala educación, arrojan sobre quienes viven dormidos, o con los ojos cerrados de par en par.

Por de pronto, en el libro sexto, se ha dejado bien sentado lo que constituye "el poder del centro". Un poder rubricado por la mitología solar que preside toda fundación tradicional de ciudades, o el gran rito inaugural mediante el cual se concedía sentido simbólico a la ciudad. En el cual la referencia al movimiento traslaticio solar era determinante de las coordenadas o meridianos que se trazaban con vistas a promover dicha inauguratio urbana.

La duplicidad platónica de la ciudad ideal y de la ciudad real, que persistentemente insiste en toda la tradición occidental (en Agustín de Hipona, en las grandes utopías renacentistas de Moro, Bacon de Verulamio o Campanella) hallan en ese rito su pertinente arqueología.

\section{IV}

Y de pronto Platón, a través de Sócrates, introduce en su Politeia el más hermoso golpe de efecto estético y gnoseológico de toda la historia de la filosofía (y quizás de la literatura). Lo que se apercibe, cuando se desciende del mundo solar al ámbito terrestre es un mundo cavernoso, en claroscuro y penumbra; como en una sala de cinematógrafo avant la lettre, o al modo de ese proyector de cine que acontece en nuestra existencia durmiente, asistimos en él, sin remisión, encadenados a la visión de lo que delante de nosotros se proyecta, a una sucesión de imágenes a las que asignamos el fuste de la realidad, siendo como son puras sombras chinescas proyectadas ante nuestros ojos alucinados. La vida misma, tal como la percibimos, posee ese ambiguo estatuto de las imágenes oníricas, sin quizás el regusto oracular de verdad escondida que el sueño real posee. 
Y la liberación sólo puede producirse a través de la educación. La política se asimila a la ardua tarea de educación, o paideia, que permitiría al prisionero librarse de las cadenas que le condenan a mirar siempre de frente, de manera que pudiese iniciar un dificultoso giro hacia los objetos que sobre la oscura pared se proyectan, dejando un saldo de sombra y claroscuro como único cómputo aceptable de realidad.

La grandeza del diálogo platónico estriba en la exigencia ética, por amor a la justicia y a la ciudad, de que una vez efectuado el ascenso sea preciso exigir a los liberados prisioneros su retorno a la caverna. Pues sólo en ella pueden realizar el objetivo y fin de la educación que se les ha dado; esa educación que les ha liberado de la servidumbre a las imágenes falsificadas. Ése es uno de los más grandes momentos, no ya del diálogo platónico, sino de toda la filosofía occidental surgida del suelo nutricio griego. Una filosofía que tiene en ese diálogo platónico su verdadera carta magna.

Hoy ese "poder del centro" ha sido radicalmente cuestionado. Desde Nietzsche, desde la alocución del loco en Die fröhliche Wissenschaft (La gaya ciencia), se vive en el cuestionamiento radical de ese Norte u Oriente que daba significación, sentido y valor a todo lo existente, y que pasa por ser, desde siempre, el "poder del centro" (con su propio y específico referente solar). Al cuestionarse ese "centro" parece como si todo perdiera dirección, orientación y sentido: los mismos puntos cardinales de nuestra orientación relativa al "arriba" y al "abajo", a la "derecha" o a la "izquierda", o al "centro" y a la "periferia". No se sabe, en consecuencia, si avanzamos o retrocedemos, si subimos o bajamos, si nos elevamos o vamos decayendo.

Pero el propio Platón había iniciado este cuestionamiento en sus grandes diálogos de madurez, en su etapa de revisión y de autocrítica. Allí se sugiere una suerte de estructura dinámica de Ideas, en permanente dialéctica, o en combinación y diferenciación, en la que lo Uno y lo Múltiple, el Ser y el No ser, la Mismidad y la Alteridad, la Limitación y lo Indeterminado, parecen apuntar a una reflexión crítica que da alas a una filosofía de nuevo cuño. En ella el mundo mismo comparece como efecto y resultado de esa movilidad inmanente de las Ideas, que en su dialéctica van creando y recreando, en combinaciones y distinciones, la trama misma de lo que existe, y de lo que puede significarse en relación con lo existente.

En esos diálogos el "poder del centro" se desplaza. Lo que es centro aparece, de pronto, como periferia. La dialéctica impide cualquier idea preconcebida sobre lo que concebimos como Uno o como Múltiple; como Mismidad o como Alteridad; como Ser o como No ser; como Límite o como Indeterminación.

Platón, en esos diálogos (Parménides, Teeteto, Sofista, Filebo), avanza y anticipa una suerte de vía posible con la que revisar, críticamente, tanto una fundación excesivamente fijada en las duplicidades de la ciudad, y del centro 
solar que dota de sentido a la urbe que se pretende fundar, como a un puro cuestionamiento negativo que sólo ofrezca, como espacio de reflexión y de experiencia, el simple saldo negativo y disolvente de esos viejos ritos inaugurales de la memoria urbana y filosófica tradicional.

En esos diálogos se apunta la posibilidad de gestar una estructura dinámica y compleja de Ideas en perpetua combinación y distinción que dan soporte y sustento a lo existente, y al sentido de lo que puede darse a experiencia (en la existencia). Y que, sin embargo, en su carácter de Ideas que dan forma a la estructura dinámica del mundo, no son reductibles a la productividad misma de una Inteligencia Especulativa que las concibe (al compás mismo de la producción de toda la trama de realidad que se nos da a experiencia).

Esa Inteligencia se halla siempre, en el gran Platón tardío, adelantada y anticipada por algo que parece siempre pre-existirle. Esa inteligencia puede dar forma a la combinación dialéctica de las ideas, pero siempre en lidia con algunas de ellas que parecen resistir toda concepción e intelección.

La ordenación de la inteligencia artesana o artística deberá "persuadir" a una suerte de potencia alógena, llamada jóra, concebida como "nodriza de huellas" y como ámbito matricial respecto a toda fundación de ciudad, o de cosmos.

La determinación y límite deberá confrontarse con el apeiron (así en las "mezclas" que la inteligencia dialéctica sugiere en el Filebo). La mismidad que se afirma se deberá confrontar con la alteridad, tó héteron, o el poder periférico de la diferencia (en pugna y tensión fecunda en relación con la identidad; así en el Sofista).

Platón funda algo más que lo que, de Nietzsche a Heidegger, solemos denominar "metafísica". Funda también el camino apropiado para una liberación del pensamiento y de la experiencia que nos permita transitar, más allá de rígidos dualismos, hacia una configuración renovada de la inteligencia, y de su modo de dotar de sentido a lo existente; a una nueva manera, por tanto, de orientarse en ese viejo oficio fundado e inaugurado por el propio Platón, al compás mismo de su fundación política y ciudadana: la filosofía.

Platón nos da alas para pensar en una filosofía que cuestione el inveterado "poder del centro", pero que no se contente con administrar las puras consecuencias disolventes que su cuestionamiento, de Nietzsche en adelante, inevitablemente promueven.

El mismo fundador de la metafísica, o de un pensamiento que intenta situarse "por encima" de los límites de lo pensable, o de lo que puede darse a experiencia, en una suerte de altitud característica de la magistratura augural, en la que se desencadena el proceso "contemplativo", ese mismo fundador puede suscitarnos las mejores pistas, en sus diálogos críticos de madurez, para emerger a un nuevo territorio del pensamiento y de la realidad, en el cual 
pueda concebirse como "poder del centro" lo que, tradicionalmente, se suele pensar siempre como "periferia".

Así por ejemplo la idea misma de Límite. Esa idea está presentida en Platón con la expresión relativa a un espacio intermedio; una suerte de "camino de en medio". Es el espacio definido como mediedad (metaxy), una suerte de ciudad fronteriza donde afincan instancias daimónicas de valencia mediadora y hermenéutica; o que permiten y posibilitan los intercambios entre lo que nos trasciende (llámese Bien, Belleza o Verdad) y nuestra existencia cavernosa, instalada en el mundo inmundo de "lo que nunca es y siempre deviene", o de la fugitiva y evanescente "irrealidad" relativa a lo que solemos denominar "realidad" y "existencia".

Y es que el mundo de sombras que en forma onírica produce efectos de aparente "realidad" sobre nuestras vidas es, sin remisión a ese espacio de la mediedad, en donde se afincan las instancias daimónicas y hermenéuticas, un cerco de apariencias sin consistencia ni significación, pero que experimentamos y vivimos, en el orden de la opinión, o de la doxa, como si fuese lo único "verdaderamente real".

En esa zona limítrofe y fronteriza instauró Platón su reflexión. En ella, y desde ella, instaló Platón, ya desde sus primeros diálogos doctrinales, un entramado de instancias intermedias que lo poblaban, dotándole de sentido: eros y poiésis, anamnesis y logos. A través de esas figuras intermedias, a mitad de camino entre la "ciudad ideal" y la "caverna", sugirió un camino fecundo para la filosofía, que en sus diálogos de madurez exploró con rigor ejemplar.

En los diálogos doctrinales, del Menón a la Politeia, fue determinando ese espacio intermedio, poblándolo de figuras anhelantes, o reminiscentes, de aquello que siempre trasciende, pero que en su cobijo (en el cerco hermético) ofrece Norte y Oriente al deseo, a la agitación de la memoria, y en consecuencia a la productividad de la inteligencia, probada en el arte de pensar, o en el ejercicio dialéctico.

En los diálogos críticos de madurez se centró en la especificación de esa tejne del pensar que es la dialéctica, la que acierta a combinar las Ideas que, en su puro automovimiento, dan fuste y estructura, siempre dinámica, a lo existente.

Concedió sujeto a esa estructura dinámica; la animó y vitalizó de un principio de automoción al que denominó Alma, psique (a mitad de camino entre la Inteligencia y los cuerpos).

De este modo fue mostrando la trama dialéctica en que esa alma, y la inteligencia que la iluminaba, iba determinando las combinaciones y distinciones que permitían comprender el significado de lo que existe, trazando los "géneros supremos" que permitían determinarlo: lo Uno y lo Múltiple (en el Parménides), el Reposo y el Movimiento, el Ser y el No ser, lo Mismo y lo 
Otro (en el Sofista), y la Determinación (péras) y lo Indeterminado (ápeiron), en justa "mezcla" a través de la Inteligencia, y en referencia al Bien y al Placer (en el orden de "lo ético"): así en el diálogo Filebo.

Esa ciudad fronteriza fue, de hecho, el gran hallazgo platónico, a través del cual rebasó y trascendió su propia instauración de un espacio meta-físico, meta-lingüístico, situado "por encima" (de lenguaje y mundo), a modo de estructura de dominación, o de gran panópticon avalado por los viejos ritos inaugurales de la "contemplación" de la magistratura del Augur, todavía evocada por Campanella con el nombre del Metafísico.

En esa ciudad fronteriza el "poder del centro" se desplaza de su centralidad solar a una suerte de periferia dialéctica en la cual la trama de las Ideas se enfrenta con sus propias aporías, o se descubre en perpetuo movimiento y giro en torno a la presión del Límite. La Idea de Unidad debe confrontarse con la Multiplicidad que la mediatiza por dentro; la de Ser con la nada; la de mismidad con la alteridad; la idea de determinación con lo indeterminado; la Idea misma, en su carácter de paradigma de creación y recreación, con el fundamento matricial que la acoge, y que en cierto modo la presiente y prefigura.

En Platón hallamos, de hecho, el alfabeto cifrado, todavía escondido bajo modos jeroglíficos, de lo que podría ser una suerte de desplazamiento de hábitos de pensamiento y de experiencia que permitan concebir el poder del centro como poder periférico, o que pueden entronizar como "piedra angular" lo que generalmente constituye una eterna "piedra desechada".

El Bien mismo, en su radicalidad, se excede y sobrepasa a su posible comprensión; lo mismo lo Uno; o la Mismidad. Sólo subsiste el cerco de luz que, en forma de poder del Límite, o como resto fecundo, suministra fuerza y poder al pensamiento y a la experiencia. Y ello exige referir de modo intrínseco lo Uno a la Multiplicidad, la Mismidad a la Alteridad, el Bien mismo a la jóra que lo sustenta y presiente.

Y eso es justamente lo que las instancias intermedias, las que habitan el espacio fronterizo, pueden registrar a través del deseo anhelante, de la reminiscencia o de la expresión dia-lógica de la propia inteligencia.

Algo de lo Bello, Verdadero y Bueno llega a esas instancias daimónicas y hermenéuticas. Y eso es justamente lo que la filosofía tiene como tarea colonizar y cultivar, fundando o re-fundando en torno a esas instancias su propio espacio de expansión y de despliegue.

El método "ascendente" que sugieren eros y anamnesis, en su remisión a lo que siempre trasciende (llámese Bien, Verdad, o Belleza) puede dar lugar a un método inverso, de gestación o poiésis, en virtud del cual se encarnen e incorporen esas tramas dialécticas y dinámicas de eterna movilidad que componen, en sus combinaciones y diferenciaciones, o en sus composiciones y escisiones, las Ideas que dan Número y Medida (musical) a lo que existe. 
De este modo la realidad se compone y descompone, o se crea y se recrea, en un eterno variarse de esa trama estructurada de ideas dinámicas cuyo inventario comenzó a efectuar en los diálogos críticos, con su apelación a los "géneros supremos". Forman esas ideas comunidad (koinonía) o muestran división entre ellas (diaíresis), de manera que van trabando y tramando la estructura móvil y dinámica, pero recurrente y reincidente, que al compás de los "géneros supremos" de Reposo y Movimiento se va formando y transformando.

Esas Ideas constituyen el entramado mismo del tapiz que va tejiendo lo que posee realidad y existencia; a la vez que va descubriendo, a la inteligencia, lo que ésta puede "declarar" (a modo de "géneros supremos"), en relación con esa realidad que la trama ideal va componiendo; componiendo y descomponiendo; pues la labor de fondo corre a cargo de los géneros que, en cierto modo, rebasan cualquier declaración "categorial": la Mismidad y la Alteridad, Mismo y Otro, tautón y tháteron, que en el Sofista asumen papel preponderante.

Esas Ideas son las que pueden fecundarse a través de la Idea crucial, nuclear, que puede servirles de gozne, de bisagra, o de eje nuclear en torno al cual circulan y se expanden, según los modos de combinación y división que el "arte dialéctico" sabe descubrir.

Esa Idea es la que en la filosofía del límite se descubre como aquella que permite declarar la verdad misma de lo que existe, y de la esencia de lo existente; la verdad ontológica, topológica y filosófica. Esa Idea es la que permite que la realidad, o lo "verdaderamente real" (ontos ón), se revele en su verdad, acogiendo dicha declaración de la inteligencia, y de sus formas de expresión.

Esa Idea fue presentida por Platón en sus últimos diálogos, concretamente en el Filebo. Se acercó a ella a través de la dialéctica entre la Idea de Determinación (limitante), en griego péras, y aquel fondo (matricial, abismal) respecto al cual tal Límite (Horos) y determinación puede ser explicitado. Lo llamó apeiron, rememorando así el origen mismo, en Anaximandro, de la gran aventura filosófica griega (y por extensión occidental). De ese fondo abismal insobornable, o de ese abismo de vastedad inconmensurable, pudo emerger de pronto, en la línea pitagórica tan visible en ese último tramo de la aventura platónica, lo que daba número y medida, circunscripción y determinación a ese apeiron.

Y de este modo fue posible, en el Timeo, sugerir la emergencia de un mundo, cosmos, que en línea con los ritos inaugurales de la ciudad diese fuste cosmológico y cosmogónico a la Idea. La Idea de Límite que permite la determinación y decisión de ordenar una suerte de vastedad inconmensurable bien preñada de huellas y de potencias. Pues ya en el Sofista había adelantado la idea de que ese ser (anterior a todo ser que existe o que se da) podía ser concebido como dynamis: potencia fundamental, o matricial, como la jóra del Timeo. 
Platón suscitó así, en su último periplo filosófico, una posible recreación de su concepto de ciudad, y de la trama ideal que hace posible la fundación de ésta, acorde con la gestación de un mundo, o del cosmos mismo, de manera que esa Idea de Límite se hallase en cierto modo presentida.

Una ciudad y un mundo fronterizo, de calidad y valencia hermenéutica, en donde hallar al fin cobijo y habitáculo a aquello que con la ciudad se corresponde: el alma, la idea misma relativa a nuestra propia condición. Pues al fin mismo de su Politeia, antes de acudir a apoyaturas mítico-poéticas, o simbólicas, en forma de complemento o suplemento (en el libro x), ya sugirió que esa ciudad hermosamente fundada, a través del diálogo (y de la escritura), era en realidad el trasunto externo del "hombre interior", o del hombre mismo, o de aquello que somos y constituye nuestra propia condición.

Esa trama de Ideas se descubren a la inteligencia dialéctica, y a sus posibles declaraciones, sobre un fondo de aporía y dificultad que muestra su peculiar desbordamiento. Son ideas que, en el límite, y bajo la presión de éste, remiten a lo que siempre se esconde; a lo que excede y desborda toda intelección; así la misma idea de Bien en el diálogo aquí convocado, en la Politeia, a la vez, en estatuto ambiguo y jánico, Idea y Sustancia de lo existente, o Esencia de cuanto aparece y se da, pero así mismo algo excedente y rebosante en referencia a toda Idea de sustancia y esencialidad: algo que se halla épekeina tês ousías.

Y esa misma remisión a lo que siempre se esconde acontece con la Idea de Uno en el Parménides, que sólo en cierto modo puede "combinar" con el ser y la existencia, o con la Idea de apeiron en el Filebo, sobre la cual puede destacarse la noción de Determinación y Límite (péras).

Y un recurso se le descubre a Platón, en su Politeia, y en general en la mayoría de sus diálogos, con el fin de colonizar, si bien de forma precaria, eso que siempre se esconde. Una suerte de talismán o de hilo de Ariadna con el cual, una vez apurados todos los razonamientos indirectos o "bastardos" (como en la concepción inducida, o metonímica, de la categoría matricial de la jóra): tal recurso es el camino de una suerte de poiésis que, en consonancia con las artes dialécticas de la inteligencia, y del razonamiento y demostración que le son propias, pueda avanzar hacia el Incógnito $(=x)$, o hacer, de manera indirecta y analógica (para decirlo al modo kantiano), que lo que siempre trasciende pueda ser expuesto y expresado.

Tal recurso es el mito; el mito ilustrado que el propio Platón está en condiciones de relatar, o de argumentar a modo de relato verosímil; el que puede propiciar una suerte de aquiescencia retórica, o de opinión bien fundada (ortha dóxa) que suscita "creencia razonable". Ese mito, entendido en sentido literal, como relato y narración, hace exégesis de lo que, siguiendo a Kant, pudiera llamarse "exposición simbólica". El mito como exégesis del símbolo 
(según fue concebido por los grandes mitógrafos románticos, de Creuzer a Bachofen).

Y es que la Idea, incluso en su formulación más ajustada, se desborda en el cerco de lo que siempre trasciende; yo suelo llamar a ese cerco, cerco hermético. Y sólo existe un recurso para avanzar y adentrarse, aunque sea de modo precario, en los misterios de los que no nos es dado conocer; por ejemplo, los misterios relativos a lo que aconteció antes de darse lo que se da, la existencia, y el mundo ("el mundo tal como me lo he encontrado", para decirlo en la hermosa expresión de Wittgenstein), y los que nos abocan al Enigma de lo que acontece en esa travesía final, o en ese estribo limítrofe, que se nos cruza con la muerte.

Y el décimo libro de la Politeia es, al respecto, una incursión en esos misterios: de lo que puede fabularse, simbólicamente, respecto a la elección de moíra (destino, asignación de parte o lote), previo a nuestro nacimiento, y al abrevarnos en el río de Leteo, donde olvidamos nuestra existencia anterior; o bien en referencia a lo que el relato de Er nos documenta: la narración de un personaje que pudo tener cierto testimonio respecto al fin final que nos aguarda, o a los misterios escatológicos en que nuestra vida halla su abocamiento con la muerte (y tras ella).

La Idea exige, pues, un suplemento (mito-poético o simbólico). Y la verdad, finalmente, se explicita como la conjunción entre esa Idea limítrofe (que Kant repensó en su primera crítica como Idea-problema relativa al Límite de lo cognoscible que, sin embargo, se nos da a pensar), y ese Símbolo que puede darle cierta exposición, si no argumental en el sentido del razonamiento, al menos en el modo mito-poético de la narración, del relato o del poema; o de los textos míticos de naturaleza sagrada.

La verdad, en última instancia, debe concebirse como la síntesis (siempre precaria) entre esa Idea (de Límite) y ese Símbolo (que da acceso a lo que rebasa y trasciende todo Límite). Yo a esa síntesis (en el Límite) de razón y simbolismo suelo llamarla Arquetipo (ya en mi libro Filosofía del futuro). Y al sujeto que podría concebirse, de manera reflexiva (a través de un juicio reflexionante) como el sujeto de esa enunciación sintética de Idea y Símbolo suelo llamarlo espíritu (así al final de mi libro La edad del espíritu).

La verdad tiene su hilo, auténtico hilo de Ariadna, en esa articulación sintética, en torno al Límite, de Idea y Símbolo que constituye el Arquetipo. Éste se crea y recrea, en variaciones de sí mismo, a través de la trama articulada y conjugada de lo que llamamos realidad, y que se descubre en las declaraciones de nuestra inteligencia (con sus configuraciones propias, lingüísticas en el más amplio sentido).

Lo que es, lo que existe y acontece es, en última instancia, un eterno retornar de arquetipos (ideas conjugadas con símbolos) que van dando con- 
sistencia a lo que es, a lo que existe y a lo que somos. En ellos vivimos y habitamos; en relación a ellos nos vamos determinando y decidiendo.

Tal es la verdad filosófica, la que corresponde a lo que iré llamando idea filosófica: una suerte de entramado de configuraciones de la inteligencia con las que la realidad, en su declaración, se descubre, cuya sustancia es a la vez ideal y simbólica. Y que dan estructura dinámica a lo existente, y le conceden significación y sentido. En el supuesto de que no son Ideas plenamente determinables por la razón (fronteriza); exigen, para ser convenientemente expuestas, el concurso de ese hilo de Ariadna que el simbolismo (y su exégesis mito-poiética) puede proporcionar.

La precaria conjunción, siempre limítrofe, entre esa trama de ideas y esas formaciones simbólicas, eso es lo que puede llamarse la estructura dinámica de arquetipos vivientes; eso que Goethe concibió como "fenómenos originarios", que sólo son y existen en su perpetua transformación, o en su peculiar modo de recrearse y variarse en sucesivas metamorfosis de sí mismos.

Platón se acercó a esta concepción; o mejor dicho, dio todas las pistas necesarias para poderla formular. Su filosofía es algo más que la fundación inaugural de una ciudad meta-lingüística, o de una especie de Ville Radiéuse impuesta, como estructura de dominación, sobre las ciudades reales existentes. Comprendió que éstas deben ser reformadas por la vía de la educación, de la paideia. O que la verdadera política es siempre reforma de la educación.

Y apuntó hacia una suerte de fundación asentada en esas instancias fronterizas en las cuales habitaban esos interlocutores del alma (y correspondientemente de la ciudad) que eran los daimones, con su peculiaridad mediadora y hermenéutica. Destacó algunos, eros, anamnesis, propiciadores de las aptitudes de comprensión e inteligencia de nuestra expresión verbal, susceptible de desplegarse en forma dia-lógica, o dia-léctica.

Y desplegó las formas adecuadas de ésta, o las más encumbradas, llamadas en sus diálogos "géneros supremos". Y comprendió también que esas Ideas o Formas, que dan estructura dinámica, en su movilidad y dialéctica, al conjunto, debían poseer, como necesario suplemento, el concurso mito-poiético de una argumentación narrada o poética, de manera que en el Límite la Idea y el Suplemento (simbólico) hallasen cierta convergencia.

A la conjunción de Idea y Símbolo en el Arquetipo le doy, en mi filosofía del límite, una significación musical. Pienso la dinámica de esa conjunción (que encierra su propia disyunción) a través del modelo o paradigma de lo que en música son las variaciones. Variaciones sobre un mismo tema que, sin embar- 
go, se va creando y recreando en ellas; como sucede con el "fenómeno originario" de Goethe.

El Ur-phoenomen es, en efecto, una suerte de arquetipo viviente (que encierra su propia Idea o Forma; y que es un símbolo encarnado). En sucesivas metamorfosis de sí mismo, se va formando y transformando. Y todo ello a partir o desde una remisión originaria al enigmático ámbito en el cual se gesta y se forja. Goethe lo llama el recinto y la morada de las Madres (unas sentadas, otras de pie y andando: formación, transformación, conservación del eterno sentido de lo existente).

Al Tema que se va recreando en el juego de las variaciones, y en su eterno retornar y reiterarse, le llamo en mi filosofía del límite ser del límite. En torno a él pueden irse determinando las declaraciones principales, o los géneros supremos, que permiten su comprensión.

Esos "géneros", de hecho, según dice Otilia en Las afinidades electivas de Goethe, son rebasados y excedidos, ya que "lo que es perfecto en su género rebasa siempre el propio género”. Son, pues, más bien lo que los escolásticos llamaban trascendentales.

Esos "trascendentales" son los que supo determinar Platón en su inventario ideal, sugiriendo su interna movilidad, animada por el sujeto de la misma, al que llamó Alma, Alma como principio de eterna movilidad, aeikinésis y autokinésis.

Alma, si quiere decirse así, insuflada de ese viento inspirador, o fuego agitado por corrientes huracanadas, que abre nuestras mentes, según el bello himno medieval de Rábano Mauro, al que da vida y forma musical Gustav Mahler en su octava sinfonía. Sólo que ese pneuma procede, más bien, de tradiciones escasamente platónicas (sobre todo de la filosofía estoica, sincrética y contaminada de ideas griegas, filosóficas, y semitas, o profético-sapienciales). Yo en todo caso, en mi filosofía del límite, en la medida en que soy y me reconozco hijo de Platón y de la Biblia, llamo Espíritu a ese sujeto.

Esa movilidad del alma es la que el arte dialéctico, verdadera téjne y epistéme propia del filósofo, definido por Platón en sus grandes diálogos de madurez crítica, sabe descubrir, acertando a destacar las articulaciones y cortes naturales entre esas ideas, o el modo de combinarse y dividirse, o de formar comunidades ideales y diferenciaciones entre ellas.

Esas Ideas ya no son entonces concebidas como Ideas Separadas sin más, sino incorporadas y encarnadas en virtud de esas instancias intermedias, cuyo principio motor era el Alma, Psique, con sus aptitudes eróticas y reminiscentes, con su apéndice de inteligencia, y de capacidad de comprensión y expresión, y con su condición de principio de animación de todo lo vivo y existente.

Y ese dinamismo y esa transformación de las Ideas, que en su modo de combinarse y diferenciarse van dando estructura y orden a lo vario y lo com- 
plejo, pudo concebirse, finalmente, en los últimos textos platónicos (y en las referencias aristotélicas a la doctrina "esotérica" de Platón en su Academia) en clave neopitagórica: como una suerte de circulación constante de Números (o Ideas-número) a través de las cuales fuera creándose y recreándose el mundo mismo, el cosmos, ya presentido en la jóra (o si se quiere decir así, en lenguaje mítico, en el jaos, "caos" hesiódico, etimológicamente bostezo, boca abierta de donde todo es arrojado).

Números que confieren medida y ritmo, armonía y sinfonía a lo existente; números que se encarnan en formas espaciales y temporales, allí donde las grandes artes de la edificación, la arquitectura y la música, artes fronterizas por excelencia, adquieren su carácter cosmológico y cosmogónico, o su peculiar téjne, siempre acorde a la téjne dialéctica de la verdadera filosofía, en virtud de la cual se trama la verdadera ciudad, la ciudad edificada sobre ese poder siempre limítrofe en el cual Alma y Ciudad hallan, en nuestra propia condición, la posible resonancia de esas instancias hermenéuticas que son eros, mnemosyne y la capacidad plasmadora (poiésis) que de ellas puede resultar.

A la composición de Idea y Símbolo la llamo Arquetipo. Este se crea y recrea en sus transformaciones; en las variaciones de sí mismo. Tal Arquetipo ronda y circula, en forma de posible análisis del mismo, en sus múltiples modos de mostrarse, o en la estructura dinámica y viva de sus manifestaciones, $o$ en la composición plural de Ideas o formas, y de remanentes simbólicos, en que El Mismo se va creando y recreando.

Al principio de esa creación y recreación le asigno el carácter de principio rector de la filosofía del límite; el que enuncia su propuesta de verdad; y su propuesta también de libertad, o de reto y envite al ethos (del fronterizo).

A ese principio, principio de variación, le doy el estatuto de lo verdadero. Dice o enuncia el Tema que en sus variaciones se va tramando, de manera que circulan a través de esas variaciones los distintos modos de mostrarse el arquetipo.

El Tema siempre es el mismo: el ser del límite que se recrea. Pero ese recrearse y variarse, en metamorfosis perpetua de sí mismo, concede a esta verdad filosófica su vivacidad real y existencial.

Las Ideas o Formas de las cosas no hacen sino destacar tal o cual aspecto o faceta (susceptible de declaración) de esa síntesis (del ser del límite que se recrea). Los símbolos lanzan antenas de productividad poiética a lo que en esa síntesis se libera siempre como resto inapropiable, o como cerco de enigma y de misterio. Yo le llamo cerco hermético.

Las Ideas y los Símbolos componen lo verdadero: los Arquetipos. Arquetipos vivientes en los que ese principio de variación se cumple. Arquetipos múltiples que remiten, en última instancia, a ese ser del límite que se recrea, que es el centro de gravedad (limítrofe, fronterizo, periférico) de una posible 
ciudad cuyo "poder del centro" se acrecienta en razón misma de la perpetua transmutación de valores que en esta filosofía se propone (como propuesta) en referencia a lo que tradicionalmente se entiende por centro y por periferia.

Un centro desplazado a la periferia que cuestiona, desde ese finis térrea del ser y del sentido, y en torno a esa idea nuclear (del ser del límite que se recrea), toda "estructura de dominación" (panopticon o Ville Radièuse) que, desde la duplicidad Ideal/Real de la vieja fundación inaugurante de las ciudades, como trasunto de la creación solar del mundo por parte de un Dios concebido como Kosmocrátor, quiera conceder ser y sentido al "mundo" (y al "lenguaje") desde "más allá" (de todo límite del pensar, del decir, de lo físico, del mundo mismo).

La ciudad fronteriza, y el principio de variación correspondiente, cuestionan esa estructura de dominación. La filosofía del límite distingue la duplicidad jánica del poder (poder del centro en sentido meta-lingüístico, como poder que perpetua y reproduce la estructura de dominación; y poder del centro desplazado a la periferia: poder del límite y del ser del límite, que en arquetipos vivientes se va creando y recreando).

Ya en Filosofía del futuro mostré que el Poder es instancia crítico-trascendental. Y es sobre todo poder en doble rostro; el poder, en su aspecto fecundo y propiciador, ángel y daimon de toda gestación poiética, o de toda poiésis, que es el poder del ser del límite (que se recrea y varía en sucesivas transformaciones de sí mismo); y también la sombra (siniestra; inhumana) que le pertenece, en razón de su misma fragilidad limítrofe y fronteriza, y que, en forma de vis inertiae (que era para Leibniz la prueba física de la existencia del pecado original, o de una suerte de perturbación del orden que afecta también al mundo, al cosmos), no hace sino reproducir, en eterna letanía monótona y monocorde, la misma estructura del Amo y del Esclavo, del Mando y de la Obediencia, del sometimiento y la sujeción, del eterno Vencedor y Vencido; el que escribe la historia oficial de las cosas, a la que se refiere Walter Benjamín en su comentario al Ángelus Novus de Paul Klee.

En Platón a veces aparecen confundidos esos dos niveles, el poder propiciador (fecundo) de creación y recreación, y su estéril sombra; el poder limítrofe, y el poder meta-físico y meta-lingüístico (o poder de dominación).

Lo mismo sucede en la Wille zur Macht de Nietzsche, donde el poder creador de estimativas y valores, o de perspectivas e interpretaciones, siempre recreado por la idea culminante de Eterno Retorno, se confunde con harta frecuencia con el poder generador de estructuras de dominación (como en la suerte de ideal resabiado y cínico a veces apelado por Nietzsche: el poder aquel que superponga la Compañía de Jesús y la confraternidad de Junkers prusiana).

De hecho el propio fundador de un modelo de Meta-ciudad (o de política cifrada en la consolidación de una estructura de dominación, que formaliza y 
perfecciona la estructura tripartita tan bien expuesta por George Dumezil como específica de la dominación indogermánica), es también quien más preciosos indicios esparce y disemina en su obra sobre lo que podría ser una ciudad alternativa, de naturaleza fronteriza, ajustada a la condición de quien está llamado a habitar y cultivar el espacio que lo define en su propia identidad y ethos: el fronterizo, el limítrofe, el posible habitante del limes; el que puede dar vida, animación y sustento a éste, o hacerlo habitable y cultivable.

\section{VI}

He intentado en este ensayo pensar en compañía de Platón; no contra Platón (como es canónico en las filosofías del siglo Xx, o en sus magnos antecedentes, de Heidegger a Derrida o Deleuze, de Nietzsche a Popper). He intentado pensar con Platón, poniendo a prueba la metodología interpretativa y hermenéutica a la que denomino recreación. Y que puede probarse en figuras filosóficas como Nietzsche, o en aventuras de creación artística y literaria (Orson Welles, Marcel Duchamp). Se trata de acercarse lo más posible a lo que puede estar vivo en ese pensamiento (o en esa forma de arte o poiésis), sobre la regla de juego de que la exégesis se efectúa en diálogo con la propuesta filosófica que aquí -y en mis libros anteriores- he ido elaborando y trazando: la que da sentido y voz a la filosofía del límite, o a la Idea filosófica a la que esa suerte de orientación corresponde.

He intentado pensar con Platón, no desde él; tampoco contra él. Pero en ese diálogo fecundo y productivo no es posible rehuir lo que radicalmente distancia esta filosofía del límite de los aspectos menos asumibles de la gran fundación platónica. Algunos se han insinuado. Pero no me daría por satisfecho si no resaltase el punto crucial que aparta, más allá de otras consideraciones, esta propuesta de la filosofía del límite de la filosofía platónica; una filosofía que siempre he tenido muy presente, desde mis primeros libros hasta los últimos.

El punto de radical distancia entre la propuesta filosófica que intento promover y Platón radica en el más problemático de su ontología y epistemología; el que a su modo ya criticó con rotundidad Aristóteles a través de su nueva ontología.

Platón no rebasa ni trasciende, en su aventura de conocimiento, el "átomo ideal" que constituye el último resto o residuo de su actividad dialéctica (de combinación y división). Su árbol del conocimiento llega hasta el "pescador de caña" del Sofista, o hasta los átomos ideales de que ya habla en el Fedro. Pero su idealismo, que corre parejo en este punto (y sólo en éste), con el hegeliano, le impide abrirse a lo que en mi libro Filosofía del futuro llamaba 
singular sensible en devenir: lo que es objeto de certidumbre sensible en el arranque de la Fenomenología del espíritu de Hegel, pero que éste debe refutar desde la potencia universalizante del lenguaje.

Aristóteles se acercó a ello al designar aquello (tode ti) que constituye el ser singular en el cual toda "sustancia" afinca e inhiere. La escuela de Duns Scoto llamó haecceitas al concepto que de ello puede desprenderse. Schelling lo denominó quoddidad (como contraposición a la esencia, quididad). Eso es aquello que, en cada variación de sí, o en toda recreación, se recrea en el modo de ideas, formas, símbolos; o arquetipos; a eso lo llamo ser del límite, que se singulariza radicalmente siempre en una existencia.

Quizás sea en el arte donde esa singularización comparece, para decirlo con Nietzsche, del modo "más transparente". Pero aquí el arte interviene como óptica de la concepción filosófica y ontológica: como fenómeno originario que descubre una dimensión del ser y del sentido de carácter primero y fundamental. Y es que en Goethe ese Urphaenomen se encarnaba siempre en singularidades específicas que permitían hacerlo visible y palpable.

Frente a lo que suponía Schiller, ese fenómeno, siempre en perpetua transformación, según el imperativo del "muere y transfórmate" (del poema Divina Nostalgia del Diván Oriental-Occidental), no era Idea Separada sino Idea encarnada (y simbólica) revelada aquí, o ahí, en un existente en devenir, susceptible de ser experimentado.

Pero esa singularidad, que el arte permite descubrir, sirve de hecho para componer una ontología y una topología, o una filosofía primera, en la que eso que siempre se varía y recrea, y que se determina según Ideas y Formas, y a través de Símbolos, y en consecuencia de Arquetipos vivientes, eso sea siempre un singular (sensible y en devenir); un singular existente, o viviente; un singular potencialmente inteligente (y libre); un singular que se recrea y varía; y que puede recrearse en virtud del gozne o la bisagra que permite esa activación o giro, o ese principio general de transformación y variación; a ese gozne, a esa bisagra, concebida en términos filosóficos, la llamo Límite (y ser del Límite). De hecho lo que en el Límite se recrea es un ser (sensible, singular, en devenir): un ser del límite que a través de Ideas y Símbolos puede hacerse accesible a la comprensión; al sentido. 